\title{
ENCONTRAR EL
}

EQUILIBRIO: VISIONES

LATINOAMERICANAS

DE LA CIUDAD,

1820-1920*

Mark Petersen $* *$

\section{La ciudad sirvió durante mucho tiempo}

como símbolo de la civilización en las sociedades que ocuparon las tierras hoy llamadas América Latina. En los siglos anteriores al encuentro de 1492, varias civilizaciones nativas sobresalieron por un urbanismo que rivalizaba con los imperios europeos de la época. Las ciudades de Tenochtitlán y Cusco, por ejemplo, cautivaron la imaginación de los europeos por su escala, belleza y organización. En el violento y caótico proceso de conquista y colonización que siguió, los colonizadores ibéricos trataron de imponer su modo de entender la civilización en una tierra que unas veces se presumía bárbara y otras edénica. La construcción de ciudades fue un aspecto importante de esa conquista, en parte porque la ciudad era fundamental para la comprensión de la civilización ibérica. Cuando los conquistadores ibéricos no se apropiaron de las estructuras urbanas existentes, erigieron otras nuevas estructuras como alegorías del orden social correcto, imbuido de un profundo significado religioso, un proceso que no era totalmente ajeno a muchos pueblos indígenas. ${ }^{1}$ La política colonial española hacia las poblaciones indígenas

* Traducción de José Manuel Orozco Garibay.

** Universidad de Dallas.

${ }^{1}$ Para una visión general de la historia de las ciudades latinoamericanas que se remonta a la conquista, véase: Richard Morse, "The urban development of Colonial Spanish America", en The Cambridge History of Latin America. Vol 2. Ed. por Leslie Bethell (Cambridge: Cambridge University Press, 1984), 67-104. Para una interesante mirada a los símbolos religiosos en las ciudades fronterizas coloniales, véase: Álvaro Félix Bolaños, "A place to live, a place to think, 
menos urbanas se centró generalmente en la “congregación”, una práctica utilizada en la Península Ibérica que concentraba a las poblaciones dispersas en pueblos o misiones con el objetivo de guiar a esas poblaciones hacia la aceptación de un orden de vida específico. ${ }^{2}$ La centralidad de la ciudad como espacio y símbolo de la civilización se convirtió en parte de la herencia de la América Latina independiente. No es de extrañar que los intelectuales, políticos y artistas latinoamericanos voltearan a la ciudad en sus esfuerzos por contemplar las realidades o posibilidades de la experiencia latinoamericana. ${ }^{3}$

La ciudad iberoamericana, tanto en la época colonial como en la poscolonial, no solo reflejaba ideales de civilización, sino que también proporcionaba espacio físico y marcos intelectuales para los debates sobre la naturaleza de la civilización. Este ensayo se centrará en uno de esos debates: ¿hasta qué punto la ciudad —y, por extensión, la sociedad en general — debería abrirse a los forasteros y a las influencias externas? Una alternativa a la apertura fue algún tipo de cierre y autarquía, que defino como autosuficiencia, no solo en lo económico, sino también en las fuentes de la cultura. Es esto último lo que interesa en este ensayo. Pocos abogaron por el cierre completo; de hecho, pocos lo consideraron una posibilidad. Sin embargo, el deseo de ver hacia dentro y limitar el acceso y la influencia de los fuereños se manifestó de varias maneras. Esta cuestión ha sido uno de los debates fundamentales en el desarrollo de las ciudades y civilizaciones de América Latina. El objetivo de este ensayo es examinar cómo generaciones sucesivas lucharon, a su manera, con esta y otras cuestiones afines durante el primer siglo (aproximadamente) de la independencia, desde la década de 1820 hasta la de 1920.

and a place to die: Sixteenth century frontier cities, plazas, and 'relaciones' in Spanish America", en Mapping Colonial Spanish America. Places and commonplaces of identity, culture, and experience. Ed. por Santa Arias y Mariselle Melâendez (Lewisburg: Associated University Presses, 2002), 275-293.

${ }^{2}$ Tamar Herzog, "Indigenous Reducciones and Spanish Resettlement: Placing Colonial and European History in Dialogue", Ler História 72 (2018): 9-30.

${ }^{3}$ La investigación sobre las ciudades en las obras de destacados intelectuales se ha tratado en otras obras, como Richard Morse, "Los intelectuales latinoamericanos y la ciudad, 1870-1940", en Ensayos histórico-sociales sobre la urbanización en América Latina. Ed. por Jorge E. Hardoy, Richard M. Morse y Richard P. Schaedel (Buenos Aires: ClACSO, Ediciones Siap, 1978), 91-112. 
En este ensayo, tras proporcionar el contexto histórico, se rastreará la cuestión en las obras de diversos individuos y grupos, prestando especial atención al argentino Domingo Faustino Sarmiento, para vincular a quienes utilizaron la ciudad como marco conceptual para pensar la civilización en el siglo XIX con los que utilizaron las ideas de la civilización para guiar el desarrollo de los espacios urbanos en el siglo XX. Aunque sus puntos de vista y prioridades eran diversas, en general sentían una necesidad de equilibrio entre la apertura y la autosuficiencia como componente esencial de la civilización.

\section{EI debate sobre la apertura como herencia colonial}

En el periodo colonial, la cuestión de la apertura o la autarquía fue el corazón del proyecto de colonización. La colonización ibérica fue, inherentemente, un proyecto de apertura del territorio y su gente a los forasteros. Este proyecto implicó tanto una imposición violenta por parte de los conquistadores ibéricos y la resistencia de los pueblos indígenas de América, como relaciones políticas y comerciales negociadas entre ambos. Sin embargo, al mismo tiempo, la colonización se concibió como un sistema cerrado. Salvo por breves lapsos, los gobiernos ibéricos trataron de controlar el flujo de comercio en sus imperios por medio de una variedad de políticas mercantilistas y una creciente burocracia imperial. También esperaban regular el movimiento de personas en las colonias. Los súbditos extranjeros generalmente requerían el permiso de la corona para entrar en estos territorios. Dentro, las leyes que dictaban la separación de las comunidades indígenas y europeas en dos "repúblicas" distintas limitaban, en teoría, la libertad de movimiento y comercio. Esta separación era más que una mera cuestión de beneficios y control político. Se relacionaba con el concepto ibérico de limpieza de sangre, que valoraba la pureza de las líneas familiares y culturales. La corona, en asociación con la Iglesia católica romana, también restringió la capacidad de enviar y hacer circular materiales impresos mediante la institución de la Inquisición — extendida a las colonias en el siglo XVI- y el control de las imprentas. Sin embargo, en la práctica, estas leyes de 
separación y los reglamentos sobre el flujo de bienes, pueblos e ideas eran difíciles de aplicar y la mezcla de las repúblicas era común.

También se debatió hasta qué punto las ciudades coloniales, símbolos del poderío ibérico en el imperio, estaban abiertas a los extranjeros. ${ }^{4}$ El hecho de que estas ciudades se ubicaran dentro de una frontera colonial complicó la cuestión de la apertura. Como colonias, la mayoría de las ciudades se mantenían a propósito dependientes de la metrópoli, España, para el tránsito de ciertos bienes. El "forastero" también era ambiguo en un espacio donde se encontraban colonizador y colonizado. Algunas ciudades coloniales, como México o Cusco, eran continuación de ciudades anteriores a la conquista, con grandes poblaciones indígenas. ¿Acaso los colonizadores ibéricos y la civilización europea trajeron consigo a los forasteros? Otras ciudades coloniales, como Lima y Santiago de Chile, fueron producto de la colonización y bastiones de la civilización ibérica en un contexto frecuentemente hostil. ¿Fueron los pueblos indígenas y su civilización los extranjeros ahí? La estructura de dos repúblicas del imperio trató de resolver esta cuestión definiendo las ciudades y las poblaciones dentro de una república particular. Aun así, los pueblos indígenas tenían una presencia casi constante en la mayoría de las ciudades ibéricas. A finales del siglo XVI, el aumento de las poblaciones de personas procedentes de África (en su mayoría, aunque no totalmente, esclavos) y de mestizos, acentuó la complejidad.

Respecto al propósito de consolidar la hegemonía ibérica en América, la apertura de la ciudad colonial tenía algunas ventajas. Llevar a "forasteros" indígenas a las ciudades ibéricas podía ayudar a introducir y normalizar a esos súbditos en el dominio ibérico y difundir así sus valores civilizatorios. La apertura de las ciudades y pueblos indígenas a los "forasteros" ibéricos podría ayudar a difundir la civilización ibérica, especialmente el catolicismo. Sin embargo, también daba lugar a la posibilidad de una transformación mutua que produjera innovación o corrupción. La preocupación por esta última permeó los comentarios coloniales escritos por observadores tanto ibéricos como indígenas. ${ }^{5}$

${ }^{4}$ Sobre las ciudades coloniales, véase: Louisa Hoberman y Susan Socolow, Cities and society in Colonial Latin America (Albuquerque: University of New Mexico Press, 1986).

${ }^{5}$ Los escritores indígenas estaban particularmente preocupados por la introducción de las costumbres ibéricas —y especialmente los vicios ibéricos — en sus comunidades. Véase, por 
En parte por el temor a un desorden social, los gobiernos coloniales se inclinaron por el cierre de pueblos indígenas y la regulación de las ciudades ibéricas. Restringieron la tenencia de la tierra dentro del centro de la ciudad a miembros prominentes de la sociedad urbana conocidos como "vecinos". ${ }^{6}$ Estos vecinos frecuentemente tenían que probar que descendían de familias ibéricas honorables o de conquistadores. También tenían que mantener una posición adecuada y honorable dentro de la comunidad. A medida que las ciudades coloniales crecieron y maduraron, esta diferenciación espacial cambió y los centros de las ciudades tuvieron mayor diversidad de clases. Sin embargo, la segregación continuó, y pasó de una orientación horizontal, en la que las élites coloniales ocupaban el centro y el resto la periferia, a una vertical, en la que las familias de la élite alquilaban las habitaciones insalubres del nivel de la calle a inquilinos de menor estatus y restringían el acceso a los pisos superiores. ${ }^{7}$ A pesar de estas restricciones legales y culturales, las ciudades coloniales nunca fueron completamente cerradas. Dependían de los bienes y la mano de obra traídos del exterior. Varias partes de la ciudad permanecieron constantemente abiertas a todos los miembros de la sociedad colonial: la plaza, donde dominaban el mercado y la Iglesia; partes de los santuarios y atrios de las iglesias; y, hasta cierto punto, el tribunal legal. Como es de esperarse, muchos de los registros que los historiadores tienen para entender las interacciones entre los diversos sectores de la sociedad colonial tienen estos espacios como escenario.

La apertura de la ciudad y la sociedad fue una cuestión importante cuando la crisis y la rebelión colonial se extendió por Iberoamérica a finales del siglo XVIII y principios del XIX. Los debates sobre la naturaleza del sistema colonial y el potencial de independencia se produjeron principalmente en los entornos urbanos. Las reivindicaciones de este periodo se centraban a menudo en la apertura, aunque no había un

ejemplo: Felipe Guaman Poma de Ayala, Nueva crónica y buen gobierno, publicada originalmente en 1615.

${ }^{6}$ Véase, por ejemplo: Douglas Cope, The limits of racial domination: Plebeian society in Colonial Mexico City, 1660-1720 (Madison: The University of Wisconsin Press, 1994), 10-26.

${ }^{7}$ Ibid., 32. 
consenso general para definir el problema. Para los revolucionarios de Buenos Aires, por ejemplo, el cierre en forma de restricciones a la libertad de comercio resultó ser una razón importante para impugnar las estructuras imperiales. Al mismo tiempo, los de Caracas resentían las políticas imperiales que habían "abierto" la política local a los "extranjeros" peninsulares, un grupo que tenía la preferencia para ocupar cargos políticos. ${ }^{8}$ Los líderes de la independencia, en un intento por legitimar sus movimientos ante una recelosa audiencia hispanoamericana, emplearon en su retórica llamamientos tanto a una mayor apertura como a una mayor autarquía. Denunciaron la tiranía española por aislar las ciudades americanas y mantenerlas en un sistema de dependencia e ignorancia. Por lo tanto, exigieron que Hispanoamérica se abriera al mundo. Simultáneamente, acusaron al gobierno español y a sus representantes en América de ser usurpadores extranjeros, y llamaron a sus compatriotas a redescubrir sus raíces americanas y a priorizar lo americano sobre lo europeo (término que generalmente significaba "peninsular").

\section{La lucha por el equilibrio en el orden posindependentista}

Aquellos que trataron de dar sentido a sus sociedades después de la independencia lograda en la década de 1820 debatieron con frecuencia el papel de la ciudad en la sociedad y hasta dónde las principales zonas urbanas debían estar abiertas a las influencias de las diferentes partes de la nueva nación y del extranjero. Andrés Bello, un intelectual y diplomático venezolano que con el tiempo se estableció en Chile, reconoció que la ciudad era un lugar importante para educar a los ciudadanos de las nuevas repúblicas. De hecho, pasó toda su vida en ciudades — de Caracas a Londres y de ahí a Santiago de Chile — y siguió su vocación intelectual y política en sus instituciones. ${ }^{9}$ Sin embargo, notó en las ciudades hispanoamericanas una tendencia a ignorar el interior y a orien-

${ }^{8}$ La historiografía de los debates de la independencia es extensa. Para un repaso sucinto de las luchas y debates, véase: John C. Chasteen, Americanos: Latin America's struggle for independence (Nueva York: Oxford University Press, 2008).

${ }^{9}$ Sobre la vida de Bello, véase: Iván Jaksic, Andrés Bello: la pasión por el orden (Santiago: Editorial Universitaria, 2001). 
tarse hacia el exterior. En su poema de 1826, "Silva a la agricultura de la zona tórrida", ${ }^{10}$ Bello denunció la decadencia urbana colonial, en la que los habitantes seguían las últimas modas europeas en lugar de la verdadera virtud. Como la virtud era inestimable para el éxito de la república, Bello llamó a los habitantes de la ciudad a abandonar sus confines urbanos, aunque fuera temporalmente, y a buscar la virtud en el cultivo de la naturaleza. Allí, a través de un trabajo honesto y una nueva educación en su tierra natal, comenzaría el renacimiento de la ciudad. Esta acción, simultáneamente, traería la prosperidad a los nuevos Estados-nación y consolidaría su independencia económica y cultural. Bello creía que la ciudad debía estar enraizada en su propio entorno y sentido de lugar, antes de que pudiera beneficiarse realmente de la apertura al mundo.

Al otro lado de los Andes, otro gigante intelectual del periodo posterior a la independencia, Domingo Faustino Sarmiento, también tenía a la ciudad como objeto de reflexión. La ciudad cumplió un papel esencial en su obra más famosa (y posiblemente más influyente), Facundo. ${ }^{11}$ Publicada en 1845, Facundo ha ocupado durante mucho tiempo un lugar en la lista de los textos más importantes producidos en América Latina en el siglo XIX. Sarmiento escribió en la tradición de Plutarco, para el cual la anécdota ofrecía una ventana al carácter del sujeto. ${ }^{12}$ Aunque Sarmiento presentaba la obra como un estudio de Facundo Quiroga, un caudillo posterior a la independencia en las Provincias Unidas del Río de la Plata, su mirada estaba puesta en un tema mucho más alto: la nueva nación de Argentina. Sarmiento escribió el texto en el exilio, despedido por la dictadura de Juan Manuel de Rosas, un caudillo que se había apoderado gradualmente del control de Argentina en las décadas de 1830 y 1840. Trató de explicar cómo Argentina había desperdiciado su promesa revolucionaria, para animar a sus compañeros liberales exiliados

${ }^{10}$ Andrés Bello, Poesías: Obras completas de don Andrés Bello (Santiago: Pedro G. Ramírez, 1883), 66-76.

${ }^{11}$ Domingo Faustino Sarmiento, Facundo, $10^{\mathrm{a}}$ edición (Madrid: Ediciones Cátedra, 2015).

${ }^{12}$ Contemporáneo y por un tiempo rival suyo fue Juan Bautista Alberti, quien le dio a Sarmiento el apodo irónico de "Plutarco de los bandidos". Citado en Celina Manzoni, "Una biografía inmoral: la vida de Aldao”, Monteagudo 3, núm. 16 (2011): 128. 
a mantener la fe y para ofrecer una refutación a la propaganda rosista. El libro llevaba frecuentemente un subtítulo, Civilización y barbarie, que sugería otro propósito humanista: reflexionar sobre las diferentes formas de vida que los individuos y las sociedades elegían perseguir. Sarmiento reflexionó sobre la naturaleza de la ciudad y, como exiliado, luchó con la cuestión de la apertura en la sociedad.

Visto superficialmente, Sarmiento atribuía la civilización a la ciudad, donde la influencia europea era más fuerte en América. En contraste, calificó la barbarie de "americana" y la vio más extendida en el campo. Si bien estos elementos del texto señalan una clara dicotomía, en la que Europa y la ciudad eran buenas mientras que América y el campo malos, se deben leer en contraste con otros temas del libro. ${ }^{13}$ Sarmiento no veía el campo argentino como inherentemente malo; albergaba una noción romántica de la grandeza y la belleza del campo y reconocía las virtudes de sus habitantes, aunque está claro que también las encontraba deficientes. Sarmiento creía que el continente americano se beneficiaba más con la apertura a las influencias europeas, especialmente a las procedentes de Francia e Inglaterra. Según Sarmiento, América tenía potencial para la civilización. De hecho, escribió que la civilización americana podría superar a la del Viejo Mundo. Europa había producido modelos de civilización, pero también había generado opresión y tiranía. España, el antiguo amo colonial, era para Sarmiento la prueba de ese punto. América tenía la posibilidad de evitar los errores de Europa.

Sarmiento propuso la ciudad europeizada como el escenario natural para la actividad civilizada en América, en especial para el comercio y la educación; sin embargo, la civilización no era una garantía en la ciudad. Dejó este punto especialmente claro en un capítulo sobre la "Sociabilidad" de la República Argentina. Allí contrastó la ciudad de Córdoba con la de Buenos Aires. Ellas, afirmaba Sarmiento, representaban dos ideales distintos de civilización. En Córdoba, situada en el interior del país, la tradición colonial española era el ideal dominante, expresado en la escolástica Universidad de Córdoba, el dominio de los

${ }^{13}$ Roberto Yahni, en su introducción al texto, afirma que Sarmiento rechazaba las simplificaciones binarias; Roberto Yahni, "Introducción”, en Sarmiento, Facundo..., 14. 
claustros religiosos en el centro de la ciudad, y en una orientación cultural e intelectual insular. ${ }^{14}$ La universidad era un lugar de educación y contemplación, pero su escolasticismo, en opinión de Sarmiento, sofocaba la libertad de pensamiento y fomentaba la decadencia más que el vigor en la investigación. Buenos Aires era todo lo contrario. Etiquetada por Sarmiento como el único y verdadero puerto marítimo atlántico del Imperio Español, Buenos Aires tenía poca historia, pero una gran apertura al mundo: era un lugar de encuentro de culturas e ideas. Aunque carecía de universidad, tenía un vibrante escenario intelectual en el que sus habitantes devoraban ansiosamente obras de filosofía, literatura y política modernas, traídas por medio de redes atlánticas a las orillas del Río de la Plata. ${ }^{15}$ Córdoba y Buenos Aires ofrecían así diferentes versiones de la civilización. Una era notable por su insularidad y por la complacencia con sus propias tradiciones; la otra, por su cosmopolitismo e integración en el mundo atlántico moderno. Esta diferencia fue más marcada durante la crisis de legitimidad imperial y el movimiento de independencia en la década de 1810. Mientras que Córdoba rechazaba las posibilidades revolucionarias, Buenos Aires estaba a la vanguardia. El futuro de la nueva república independiente, por lo tanto, estaba en Buenos Aires, con apertura más que con autarquía.

Sin embargo, algo salió mal en las décadas de 1820 y 1830. En lugar de llevar al país hacia la libertad, Buenos Aires sucumbió a la guerra civil, a la inestabilidad y a la tiranía que se había extendido por las provincias desde el periodo de la independencia. Sarmiento identificó la apertura ingenua como una de las causas de este destino. Los revolucionarios liberales de Buenos Aires habían abierto la ciudad al mundo y le habían dado al país un gobierno basado en las mejores ideas de Europa y América del Norte. Esto proporcionó unos cimientos firmes a la nueva nación (que sobrevivieron de alguna forma, incluso cuando Argentina cayó en la tiranía) pero no garantizaba el éxito. Los arquitectos de este esquema enfrentaron un grave desafío: “¿cómo ponerle rienda al vuelo de la fantasía del habitante de una llanura sin límites, dando frente a un río sin ribera opuesta, a un paso de la Europa sin conciencia de sus propias

${ }^{14}$ Sarmiento, Facundo..., 167-73.

${ }^{15}$ Ibid., 173-82. 
tradiciones, sin tenerlas en realidad?". Desafortunadamente, esta falta de autoconciencia persistió. En efecto, "Buenos Aires se entregó a la obra de constituirse a sí, y a la República, como se había entregado a la de libertarse a sí y a la América, con decisión, sin medios términos, sin contemporización con los obstáculos". ${ }^{16}$ La inestabilidad producida en este drástico cambio abrió el camino para que Rosas, gobernador de la Provincia de Buenos Aires, usurpara el proyecto revolucionario.

Rosas aprovechó la oportunidad, tomó el control de la ciudad y, según Sarmiento, la corrompió. Revirtió el programa liberal de libre comercio y el fortalecimiento de los lazos con las potencias europeas, y postuló en su lugar una forma de republicanismo "americano" que despreciaba las modas europeas y celebraba al gaucho. Limitó las importaciones de productos europeos, amañó las elecciones, censuró la prensa y persiguió a sus críticos, los liberales "unitarios", enemigos del pueblo argentino. Para no confundir su programa político, su lema era "Muerte a los unitarios salvajes". Para Sarmiento, Rosas era el villano máximo: un personaje frío y calculador que usaba su considerable riqueza y educación para manipular a las masas y convertir las herramientas de la civilización en las armas de la tiranía arcaica. La ciudad de Buenos Aires, antaño floreciente en un aire de libertad, se convirtió en el centro de una red tiránica de déspotas provinciales y brutalidad policial. Las circunstancias personales de Sarmiento influyeron en su punto de vista sobre Rosas, y exageró a efectos de su argumento más amplio sobre la civilización. ${ }^{17}$ Este punto, sin embargo, subraya lo problemático que Sarmiento creía que era la autarquía excesiva.

Sarmiento alentó, pues, la reapertura de Argentina al comercio, a las ideas, al capital y a la inmigración europeos, pero también advirtió que no se debía ir demasiado lejos e imitar superficialmente a Europa. Para contrarrestar esto, Sarmiento sostuvo que los proveedores de la civilización necesitaban enfrentarse a las realidades de sus circuns-

${ }^{16}$ Ibid., 177.

${ }^{17} \mathrm{El}$ legado de Rosas ha sido objeto de un intenso debate histórico desde el siglo XIX. Para una introducción concisa a esa historiografía, véase: Jeffrey Shumway, "Juan Manuel de Rosas: Authoritarian caudillo and primitive populist”, History Compass 2, núm. 1 (2004): 1-14. 
tancias y buscar un cambio más profundo en la sociedad argentina mediante el desarrollo nacional y la educación. Sus consideraciones lo llevaron, con el tiempo, a ver a los Estados Unidos — con su constitución y su extenso sistema de educación pública - como un modelo. En última instancia, pues, Sarmiento abogó por una ciudad que se equilibrara entre la apertura a las influencias externas y la conciencia de las realidades internas. En obras posteriores, Sarmiento mantuvo la necesidad de apertura a Europa, así como la preocupación de que esta pudiera ir demasiado lejos. En 1881 (después de la caída de Rosas en 1852, el regreso de Sarmiento a la Argentina, y su turno como presidente de la república de 1868 a 1874) Sarmiento reflexionó sobre el estado de la nación, especialmente sobre la creciente ola de inmigración europea a Buenos Aires y al resto de la Argentina. Lamentó que muchos de los inmigrantes, especialmente los de Italia, recibieran su educación en escuelas italianas con poca o ninguna enseñanza de historia española o argentina. ${ }^{18}$ La apertura tenía que ir en ambos sentidos: Argentina tenía que abrirse a las influencias europeas y los europeos tenían que abrirse a convertirse en argentinos. Desafortunadamente, no extendió esta apertura mutua a los pueblos indígenas de Argentina. Sarmiento perpetuó la idea colonial de que la ciudad era un transmisor de la civilización europeizada en una tierra de barbarie "americana".

El conocimiento de las realidades internas, incluido el de la presencia de comunidades indígenas, era necesario para conquistarlas. Siguiendo las perspectivas racialistas y racistas de su tiempo, Sarmiento entendió la comprensión de la condición indígena como un medio para superarla. La ciudad de Sarmiento estaba abierta a la influencia europea, pero cerrada a las nociones indígenas de civilización.

${ }^{18}$ Diana Sorenson Goodrich, Facundo and the construction of Argentine culture (Austin: University of Texas Press, 1996) y Michael Goebel, "Inmigration and national Identity in Latin America, 1870-1930", en Oxford Research Encyclopedia of Latin American History, https://oxfordre.com/latinamericanhistory/view/10.1093/acrefore/9780199366439.001.0001/ acrefore-9780199366439-e-288 


\section{Las consecuencias de la imitación excesiva en la era de la exportación}

Muchos gobiernos y planificadores urbanos de finales del siglo XIX en América Latina parecieron aceptar el llamamiento de Sarmiento a la apertura a la civilización europea. En la década de 1870 había consenso entre las élites dirigentes de muchos países latinoamericanos sobre los beneficios del comercio y la inversión europeos. La riqueza producida por la exportación de materias primas en esta época de oligarquía liberal financió la renovación de las capitales de toda la región. Las élites políticas y económicas de América Latina se inspiraron en la renovación de París a mediados de siglo realizada por el Barón von Haussmann, y emplearon tecnologías y materiales modernos para dar a sus ciudades un aire decididamente europeo. ${ }^{19}$ Las antiguas cuadrículas coloniales dieron paso a amplios bulevares y edificios estilo beaux-arts. Al igual que las ideas revolucionarias de la década de 1810, las tecnologías de finales del siglo XIX parecían desanclar a estas sociedades de la realidad del tiempo y el lugar. Las otrora soñolientas ciudades provinciales emprendieron grandes proyectos arquitectónicos. Manaos, una ciudad surgida del auge del caucho en medio del Amazonas brasileño, erigió una magnífica ópera italiana en la década de 1880, con azulejos franceses, acero escocés y mármol italiano. Mientras tanto, la demografía de algunas ciudades latinoamericanas cambiaba a medida que los gobiernos alentaban la inmigración europea para reforzar la oferta de mano de obra y, en consonancia con el racismo pseudocientífico en boga en ese momento, para "blanquear" a sus poblaciones. El Cono Sur, Brasil, Cuba y México atrajeron el mayor número de inmigrantes. En las primeras décadas del siglo XX, la población bonaerense nacida en el extranjero se convirtió en mayoritaria.

Los intelectuales reconocieron las complejidades del desarrollo urbano en este contexto; las ciudades eran el lugar de las virtudes positivistas del progreso, así como de los vicios de la delincuencia y la enfermedad. ${ }^{20}$ Desde el desierto del exilio político volvieron a sonar voces de

${ }^{19}$ Véase: Arturo Almandoz, Planning Latin America's capital cities, 1850-1950 (Londres: Routledge, 2002).

${ }^{20}$ Morse, "Los intelectuales latinoamericanos", 92-100. 
preocupación, esta vez no como una advertencia de excesiva autarquía, sino más bien de excesiva apertura. Curiosamente, estas voces representaban un conjunto diverso de posiciones políticas: revolucionarias, conservadoras y liberales. El cubano José Martí, expulsado de la "isla siempre fiel” por su apoyo a la independencia de Cuba, reprendió a los intelectuales latinoamericanos por olvidar su americanismo. En su famoso ensayo "Nuestra América" de 1891, comparó a América Latina con una ciudad en la que los dirigentes estaban tan preocupados por sus propias rivalidades parroquiales que ignoraban la amenaza más acuciante: el imperialismo, especialmente del creciente coloso de los Estados Unidos. ${ }^{21} \mathrm{Al}$ criticar a las élites latinoamericanas, Martí se centró en su ignorancia de su propio país. “¿Cómo han de salir de las universidades los gobernantes — preguntó-, si no hay universidad en América donde se enseñe lo rudimentario del arte del gobierno, que es el análisis de los elementos peculiares de los pueblos de América? A adivinar salen los jóvenes al mundo, con antiparras yanquis o francesas, y aspiran a dirigir un pueblo que no conocen." 22 Con la máxima "conocer el país, y gobernarlo conforme al conocimiento, es el único modo de librarlo de tiranías", Martí llamó a la reeducación revolucionaria de América Latina y a una reorganización de sus sociedades hacia lo auténticamente americano. ${ }^{23}$ Sus escritos circularon por toda la región y ayudaron a inspirar movimientos intelectuales y políticos que finalmente adoptaron la etiqueta de "latinoamericanismo".

En Brasil, una advertencia contra el cosmopolitismo desenfrenado apareció en una serie de artículos autobiográficos del intelectual y estadista conservador Joaquim Nabuco. ${ }^{24}$ Después de haberse opuesto al establecimiento de la república brasileña en 1889, el monarquista Nabuco se encontró en un exilio interno en la década de 1890. Sin poder político, siguió siendo sin embargo una figura famosa dedicada al servicio público. Cuando una revista brasileña le pidió a Nabuco que reflexio-

${ }^{21}$ José Martí, "Nuestra América", en Obras Completas, Volumen 6: Nuestra América (La Habana: Editorial de Estudios Martianos, 2011), 15-23.

${ }^{22}$ Ibid., 17.

${ }^{23}$ Ibid., 20.

${ }^{24}$ Joaquim Nabuco, My formative years. Trad. por Christopher Peterson (Oxford: Signal, 2012). 
nara sobre lo que había inspirado sus escritos y su política, reconoció la oportunidad de ayudar con sus memorias a guiar a la nación a través de las primeras turbulencias republicanas. Las ciudades, esta vez en Europa, resultaron útiles para considerar los caminos que le esperaban a Brasil. Al reflexionar sobre sus estancias anteriores en Europa, Nabuco destacó el contraste entre París y Londres. París era, para Nabuco, "una obra de arte, inmortalmente bella", una ciudad que "combina el arte con la alegría de vivir en sus formas más delicadas y elegantes". 25 Sin embargo, Nabuco notó que "en París, la vida era una limitación [...] era una esclavitud, una esclavitud al arte, al espíritu, a la etiqueta, a la sociedad, una esclavitud agradable, pero siempre una esclavitud que exigía una constante auto-vigilancia del actor ante el público”. Al tratar de ser universal, se había perdido a sí mismo. Londres, por otro lado, era "independencia, naturalidad y despreocupación". ${ }^{26}$ Mientras que París se deleitaba con una exuberancia caótica, Londres ofrecía dignidad, silencio y confianza, arraigadas en la "máxima expresión de fuerza y soberanía; no es una ciudad cosmopolita esta metrópoli del mundo: es una ciudad inglesa". Para Nabuco, los ingleses habían encontrado el equilibrio adecuado entre la apertura al mundo y el respeto por el carácter nacional y la tradición. Este era el desafío para la civi24 lización brasileña.

En 1900 aparecieron los artículos de Nabuco en un solo volumen, Minha Formação. Ese mismo año, un joven profesor de filosofía uruguayo llamado José Enrique Rodó publicó sus pensamientos sobre el problema de la excesiva imitación en su influyente ensayo Ariel. Para Rodó, las élites de la región estaban demasiado abiertas a la influencia de Estados Unidos, condición que él denominó “nordomanía" ${ }^{27}$ Aunque Rodó admiraba el progreso que había logrado Estados Unidos, creía que la sociedad estadounidense, expresada en sus ciudades, había sucumbido al materialismo y a la mediocridad democrática. La noble "tradición washingtoniana" de la virtud cívica y la libertad sobrevivió, pero estaba subordinada a los valores occidentales del progreso material.

${ }^{25} \mathrm{Ibid}$., 62.

${ }^{26}$ Ibid., 61-62.

${ }^{27}$ José Enrique Rodó, Ariel y Proteo selecto (Caracas: Biblioteca Ayacucho, 1993), 41. 
“Chicago se alza a reinar”, observó Rodó. ${ }^{28}$ La solución de Rodó para este mal en América Latina fue una reorientación hacia la belleza y el idealismo, que prescribió mediante el uso de analogías urbanas. América Latina debía abrazar su vocación como el contrapeso espiritual de un Estados Unidos materialista en el eje de la civilización americana, como las ciudades-Estado de Atenas y Esparta lo habían sido para la antigua Grecia. ${ }^{29}$ Sus ciudades habían de ser más que meros centros de acumulación de riqueza; eran sitios donde "los arrabales de su espíritu alcanzan más allá de las cumbres y los mares". ${ }^{30}$

\section{Diseñar la modernidad latinoamericana en el siglo $\mathrm{XX}$}

A partir de estos argumentos políticos y filosóficos, en las primeras décadas del siglo XX muchos grupos responsables del diseño de las ciudades comenzaron a abogar por espacios urbanos auténticamente latinoamericanos. Objetaron la estética formal "académica" inspirada en modelos franceses y, en cambio, exploraron el diseño "orgánico" inspirado en las culturas nacionales y locales. Los arquitectos de México y el Cono Sur dirigieron inicialmente la conversación, reaccionando a las celebraciones del centenario de la independencia, el nacionalismo cultural literario y la Revolución Mexicana de 1910. ${ }^{31}$ Esta nueva estética "americana" buscaba revivir las tradiciones indígenas e ibéricas utilizando técnicas modernas de diseño y construcción. Las ideas para estos estilos circularon en reuniones regionales de arquitectos y en las páginas de las revistas de arquitectura de América Latina. ${ }^{32}$ La revista argentina El arquitecto, por ejemplo, publicó en 1920 el "Ensayo de arquitectura americana” de Héctor Greslebin y Ángel Pascual. Incluía un plan para un "Mausoleo Americano" que incorporaba múltiples

${ }^{28} \mathrm{Ibid}$., 54.

${ }^{29}$ Ibid., 43.

${ }^{30}$ Ibid., 60.

${ }^{31}$ Ramón Gutiérrez, Arquitectura y urbanismo en Iberoamérica (Madrid: Cátedra, 1983), capítulo 20.

${ }^{32} \mathrm{El}$ argentino Martín Noel publicó un llamado para una arquitectura regional: "Nacimiento de la Arquitectura Hispana-Americana", Revista de Arquitectura 1, núm. 1 (1915): 8-12. 
influencias indígenas de Mesoamérica y del mundo andino. ${ }^{33}$ El resultado fue una visión de la modernidad definida por América Latina, más que por Europa o Estados Unidos. ${ }^{34}$ Estas ideas de diseño no eran necesariamente "auténticas" para los espacios urbanos que agraciaron. A menudo difuminaban las líneas entre las identidades regionales y nacionales, lo que complicaba la cuestión de la apertura a las fuerzas externas. También se basaban más en la nostalgia y el romanticismo que en el realismo histórico, un pasado imaginario adaptado a las demandas y proyectos políticos modernos. Por ejemplo, la arquitectura neocolonial popular en América del Sur evocaba el pasado hispánico en un momento en que las conexiones culturales revitalizadas con España servían para contrarrestar el imperialismo estadounidense e impugnar los argumentos de inferioridad latinoamericana inherentes a ese imperialismo.

Los arquitectos latinoamericanos que participaron en esos debates también reclamaron planes más ambiciosos de renovación urbana. La inmigración y la migración interna habían aumentado rápidamente la población urbana en muchas partes de América Latina. A medida que los gobiernos luchaban por abordar las tensiones sociales exacerbadas por este crecimiento, recurrieron a expertos técnicos para encontrar soluciones. Los ingenieros civiles y los urbanistas profesionales ofrecían 26 la promesa de la precisión científica y las técnicas modernas, y a menudo recurrían a ejemplos del extranjero. Los arquitectos, preocupados tanto por el posible malestar social como por la amenaza de perder terreno frente a las profesiones competidoras, creían que este enfoque fracasaría. Citando a Rodó, sostuvieron que las poblaciones urbanas necesitaban algo más que un transporte eficiente o el acceso a una

${ }^{33}$ Héctor Greslebin y Ángel Pascual, “Un ensayo de Arquitectura Americana”, El Arquitecto 1, núm. 12 (1920): 231-244.

${ }^{34}$ Sobre el neocolonialismo como modernismo, véase: Verónica Cremaschi, "El estilo neocolonial como modernismo iberoamericano", Arquitecturas del Sur 32 (2014): 64-75. Este estaba lejos de ser la única forma —o la dominante - de arquitectura modernista en América Latina. Véase: Mauro F. Guillén, "Modernism without modernity: The rise of modernist architecture in Mexico, Brazil, and Argentina, 1890-1940", Latin American Research Review 39, núm. 2 (2004): 6-34. Para modernidades alternativas e intelectuales del siglo XX, véase: Nicola Miller, Reinventing modernity in Latin America: Intellectuals imagine the future, 1900-1930 (Nueva York: Palgrave Macmillan, 2008), y Rebecca Earl, The return of the native: Indians and mythmaking in Spanish America, 1810-1930 (Durham: Duke University Press, 2007). 
vivienda asequible. Necesitaban belleza para contemplar, diseño para elevar el espíritu y monumentos para cultivar un sentido adecuado de nacionalismo. ${ }^{35}$

En estos debates, la cuestión de la apertura a la influencia exterior causó divisiones. Por un lado, algunos arquitectos instaron a sus colegas regionales a adoptar las ideas de la planificación urbana moderna que surgían entonces en Europa. Las obras del francés Léon Jaussely y del suizo Le Corbusier ganaron adeptos en América del Sur, especialmente en Brasil. Estas nuevas ideas daban prioridad a la ingeniería sobre la ornamentación, sugerían una reorganización radical del espacio urbano y proponían un estilo universal o internacional. Le Corbusier visitó Sudamérica a finales de la década de 1920, con la esperanza de que el Nuevo Mundo ofrecería mayores oportunidades para el revolucionario rediseño del espacio urbano que imaginaba. ${ }^{36}$ Otros arquitectos se burlaron de estas ideas, a las que tenían como impuestas desde fuera e incongruentes con las realidades latinoamericanas. En cambio, pedían un diseño urbano más "orgánico" que reconociera y mejorara los patrones urbanos existentes y diera prioridad a los estilos neocoloniales y nacionales que habían surgido en la década de 1910. Algunos incluso apoyaron que se abrieran los concursos para comisionar construcciones públicas solo a candidatos con credenciales nacionales. ${ }^{37}$ En varios congresos regionales de arquitectos celebrados en las décadas de 1920 y 1930 se llegó gradualmente a un consenso. Los arquitectos acordaron que imponer una preferencia desde arriba sería una limitación innecesaria. En cambio, los arquitectos de cada nación deberían buscar su propia combinación de influencias extranjeras y autóctonas en función de

${ }^{35}$ Los arquitectos que asistieron al primer Congreso Panamericano de Arquitectos de Montevideo abrieron su sesión inaugural con un brindis en honor de Rodó. Véase: Comité Ejecutivo del Congreso, Primer Congreso Pan-Americano de Arquitectos: Montevideo, Marzo 1 a 7 de 1920: Actas y Trabajos (Montevideo: Imprenta y Casa Editorial Renacimiento, 1921). Para un análisis y una visión global de los congresos, véase: Ramón Gutiérrez, Jorge Tartarini y Rubens Stagno, Congresos Panamericanos de Arquitectos, 1920-2000: Aportes para su historia (Buenos Aires: CEDODAL, 2007).

${ }^{36}$ Ramón Gutiérrez, ed., Le Corbusier en el Río de la Plata, 1929 (Montevideo: CEDODAL y FADU, 2009).

37 “'Segundo Congreso Panamericano de Arquitectos”, Arquitectura 9, núm. 71 (1923): 223. 
su contexto particular. ${ }^{38}$ En otras palabras, apoyaron un "organicismo abierto" paralelo a otros desarrollos arquitectónicos en otros lugares, en particular el de Frank Lloyd Wright en Estados Unidos.

\section{Conclusión}

La ciudad ha sido un espacio para grandes debates sobre la naturaleza de la civilización en América Latina, y también ha ocupado un lugar importante en la imaginación de destacados intelectuales de la región. Bello, Sarmiento, Martí, Nabuco y Rodó recurrieron a las ciudades —reales, históricas e imaginadas - como ejemplos y marcos para considerar los desafíos que enfrentaban sus respectivas sociedades, incluido el debate sobre la apertura y la insularidad. Sus escritos dan fe de la complejidad de esta cuestión y del complicado significado de la ciudad, que es a la vez el lugar de la virtud y la decadencia, de la libertad y la tiranía, del (neo)colonialismo y el nacionalismo. A pesar de sus diferentes enfoques y contextos, la mayoría de estos autores compartían la preocupación por el equilibrio entre las influencias externas e internas en la definición de sus sociedades. América Latina y las naciones que la componen debían abrirse al mundo, pero sin olvidarse de sí mismas. Ese enfoque no se limitaba a las páginas de los textos políticos y académicos. Como demostraron los arquitectos sudamericanos del siglo XX, aquellos que participaron en el diseño de las florecientes ciudades de América también consideraron esta cuestión y llegaron a respuestas similares. Conforme avanzó el siglo, la región llegó a ser la más urbanizada en el mundo por el porcentaje de población que vivía en zonas urbanas. Los debates sobre si definir la civilización en función de modelos del exterior o de fuentes del interior siguieron causando controversia. Sin duda, la búsqueda de un equilibrio entre la apertura y la insularidad seguirá siendo una cuestión relevante para las sociedades latinoamericanas.

${ }^{38}$ Gutiérrez et al., Congresos..., 12-16. 